Acta Technologica Agriculturae 2

Nitra, Slovaca Universitas Agriculturae Nitriae, 2019, pp. 64-69

\title{
DETERMINATION OF TOXIC METALS CONTENT IN IRANIAN AND ITALIAN FLAVOURED OLIVE OIL
}

\author{
Parisa ZIARATI $^{*}$, Fatemehsadat MIRMOHAMMAD MAKKI ${ }^{2}$, Sergij VAMBOL ${ }^{3}$, Viola VAMBOL ${ }^{3}$ \\ ${ }^{1}$ Nutrition and Food Sciences Research Center, Tehran Medical Sciences, Islamic Azad University, Tehran, Iran; \\ ${ }^{2}$ Islamic Azad University, Tehran, Iran \\ ${ }^{3}$ Berdyansk State Pedagogical University, Berdyansk, Ukraine
}

\begin{abstract}
Cultural practices and control of diseases and insects are widely used for cultivation of Olea europea L. These are considered potential contaminants. Aim of this investigation lies in determination of concentrations of contaminants in several edible olive oils. All test samples were purchased in three consecutive seasons. They were analysed in compliance with standardized international protocols of wet digestion methods. Ion concentrations were determined in three replicates using method of inductively coupled plasma optical emission spectrometry. We have registered a positive correlation between storage time and heavy metals contents. It was particularly high in Iranian brands and varied significantly. Investigation results show that all obtained heavy metals contents in pepper-flavoured olive oil samples were significantly lower than in other samples. Considering the fungi-flavoured samples, levels of $\mathrm{Pb}$ and $\mathrm{Cd}$ were prominent and exceeded the maximum permissible level set in the majority of cases. The further monitoring is needed as all these metals are toxic and their detrimental effect becomes obvious only after several years of exposure.
\end{abstract}

Keywords: flavoured edible olive oil; inductively coupled plasma; toxic metals; food safety

Olive tree (Olea europea L.) is a subtropical commonly occurring in Mediterranean countries (Ziarati and Tosifi, 2014). In regards to the latest report issued by the European Commission (European Commission, 2012), olive oil is primarily manufactured in Spain (2.4 mil. ha), Italy (1.4 mil. ha), Greece ( 1 mil. ha) and Portugal ( 0.5 mil. ha). Vegetable oils are commonly utilized for cooking and food processing, as well as in cosmetics; furthermore, numerous products processed by pharmaceutical and chemical industries contain it (Covas, 2007; Pehlivan et al., 2008).

Cultural practices and control of diseases and insects represent essential aspects in provision of crop production efficiency (Shahgholi et al., 2015). They are potential sources of contamination. Contamination sources may also be related to wastes utilization (Vambol et al., 2018) or storage locations (Vambol et al., 2017). Application of nutrients is strictly important (CODEX STAN 33-1981, 1981). All products must comply with requirement of maximum contamination concentration limits established by the Codex Alimentarius Commission. Currently, following limits should be obligatory: the maximum concentration limit is $0.1 \mathrm{mg} \cdot \mathrm{kg}-1$ for lead (Pb); it is $0.1 \mathrm{mg} \cdot \mathrm{kg}^{-1}$ for arsenic (As). United States Department of Agriculture (USDA) has also established the maximum permissible level of simultaneous heavy metals content equal to $0.1 \mathrm{mg} \cdot \mathrm{kg}^{-1}$ for both $\mathrm{Pb}$ and As (Jafari Moghadam and Ziarati, 2016).

Several studies show that phenolic compounds have important role in preventing cardiovascular and neurodegenerative diseases, diabetes mellitus and cancer
(Mailer, 2006; Waterman and Lockwood, 2007; RodríguezMorató et al., 2015). It is known that olive oil improves several cardiovascular risk factors, perhaps due to reduced level of plasma cholesterol and triglycerides (Huang and Sumpio, 2008; International Olive Council, 2012).

There are many different methods for analysing of various compounds of olive oils:

- liquid chromatography coupled with mass spectrometry for determination of sterols (Becerra-Herrera et al., 2014); - liquid chromatography-triple-quadruple mass spectrometry for determination of phenolic compounds (Garcia Mesa and Mateos, 2007);

- pH-basedflow-injection analysis system for determination of bitterness and total phenolic compounds (GodoyCaballero et al., 2012);

- nonaqueous capillary electrophoresis with ultravioletvisible and fluorescence detection for fast determination of phenolic compounds (Canabate-Diaz et al., 2007);

- high-performance liquid chromatography-mass spectrometry (HPLC-MS) for separation and determination of sterols and determination of heavy metals and trace elements by means of inductively coupled plasma atomic emission spectrometry (ICP-AES), inductively coupled plasma mass spectrometry (ICP-MS), atomic absorption spectrometry, inductively coupled plasma optical emission spectrometry (ICP-OES) (Covas, 2007; Flores et al., 2009; World Health Organization, 2011; Pehlivan et al., 2008; Zhang et al., 2014; Farzin and Moassesi, 2014).

Contact address: Parisa Ziarati, Nutrition and Food Sciences Research Center, Tehran Medical Sciences, Islamic Azad University, Tehran, Iran, 1941933111, e-mail: ziarati.p@iaups.ac.ir 
Heavy metals may get into the human body with the food, fruits or vegetables. Currently, the highest concern of both the environmental and human health specialists is As contamination (Mirmohammad Makki and Ziarati, 2014). Predominant and also the most toxic form of this element under reductive conditions is As(III). Furthermore, concentration of dissolved arsenic in water rises with increasing water $\mathrm{pH}$ value (Singh et al., 2007). $\mathrm{Pb}$ is another toxic substance deteriorating multiple human body organs and systems. It has comparatively small range between safe exposure and fatal dose (United States Department of Agriculture, 2010). One more highly toxic element is cadmium (Cd) transferred to food from fertilizers and packaging (World Health Organization, 2011). The fourth heavy metal in the focus of this study is nickel (Ni), which is an essential trace metal for several animal species, microorganisms and plants (Council of Europe, 2001).

Primary goal of this paper is to determine contents of $\mathrm{As}, \mathrm{Pb}, \mathrm{Cd}$ and $\mathrm{Ni}$ in olive oil samples, both non-flavoured (virgin and extra-virgin) and flavoured (with fungi, aroma vegetables and pepper) ones, commercially available on Iranian market, and their comparison with Italian samples.

Toxic elements contents of olive oil samples are evaluated in terms of their potential to pose a health risk to consumers. Established elements concentrations were compared with the current legal standards applied in the European Union concerning heavy metals in food. Potential health effects are assessed in the light of the weekly intake limits of $\mathrm{Pb}, \mathrm{As}, \mathrm{Cd}$ and $\mathrm{Ni}$ set by the WHO and FAO of the UN (Codex Alimentarius Commission, 2001).

\section{Material and methods}

Olive oil samples for investigation were purchased in the selected areas of recognized markets in Iran and Italy. Samples were analysed using standardized international protocols of wet digestion methods. Every precaution necessary for preventing any sample contamination was taken (Singh et al., 2007; Jafari Moghadam and Ziarati, 2016). There were collected both non-flavoured (virgin and extra-virgin) and flavoured (with fungi, aroma vegetables and pepper flavours) olive oils. In total, 480 samples were randomly taken from food supply markets from the provinces of Lombardi in Italy and Tehran from Iran. All olive oil samples were purchased in autumn 2016 and later in winter and spring 2017. For each location, cultivars dominant in the respective area were selected. Olive samples were collected during the period appropriate for oil production. Single sample contained $500-1,000 \mathrm{~g}$ of fruits. These were manually collected from the same three trees and preserved at the temperature of $+4{ }^{\circ} \mathrm{C}$. Quantitative determination was made for heavy metals analysis. All containers used for sample collection were cleaned using liquid soap, rinsed with water, soaked in 10\% nitric acid for at least one night, rinsed richly in deionized water and dried in order to avoid contamination. In order to ensure accuracy, certified standard reference material (Alpha - Line, Chem Tech Analytical, England) was applied. All recoveries of the metals observed exceeded $95 \%$. $\mathrm{Cd}, \mathrm{Pb}$ and $\mathrm{Ni}$ ion concentrations were determined in three replications by means of Varian Vista ICP-AES device. The intra-day (for samples collected during the same day) and inter-day (for samples collected during different days) precision and accuracy of the method were determined under the optimal working conditions by triplicate measurements of known $\mathrm{Cd}, \mathrm{Ni}$ and $\mathrm{Pb}$ concentrations. The first standard stock solutions showed a $1.0 \mathrm{mg} \cdot \mathrm{l}^{-1}$ concentration of each metal and aqueous standard solutions were prepared from them by means of appropriate dilution with $10 \%$ nitric acid. The working solutions showed concentration ranges of 0.001-0.1 ppm (Ziarati, 2012; Ziarati and GhasemynezhadShanderman, 2014).

\section{Quantitative determination of As}

As(III) stock standard solution was prepared by weighing of $0.053 \mathrm{~g}$ of $\mathrm{As}_{2} \mathrm{O}_{3}$ which was dissolved in $1 \mathrm{mmol} \mathrm{NaOH}$ with concentrated $\mathrm{HNO}_{3}$. Subsequently, its volume was made up to $100 \mathrm{ml}$ with deionized water in the flask and the $\mathrm{pH}$ of solution was adjusted. At the same time, $\mathrm{As}(\mathrm{V})$ stock standard solution was made by weighing of $0.0551 \mathrm{~g}$ of $\mathrm{As}_{2} \mathrm{O}_{5}$ and its volume was adjusted to $100 \mathrm{ml}$ with deionized water. The standard working solutions of $50 \mu \mathrm{g} \cdot \mathrm{l}^{-1}$ of As(III) and $\mathrm{As}(\mathrm{V})$ were prepared by proper dilution of the stock standard solutions described above (Chooto et al., 2016).

\section{Preparation of $\mathrm{NaBH}_{4}$ solution}

The solution of $0.4 \% \mathrm{NaBH}_{4}$ was used as reductant solution. It was prepared fresh each day by weighing of $1 \mathrm{~g}$ of $\mathrm{NaBH}_{4}$ and $1.25 \mathrm{~g}$ of $\mathrm{NaOH}$ dissolved with deionized water up to a final volume of $250 \mathrm{ml}$ (Chooto et al., 2016).

\section{Preparation of samples}

An aliquot of $3.0 \mathrm{~g}$ of each oil was weighed directly into the polypropylene containers. Subsequently, $1 \mathrm{ml}$ of the $10 \%$ dilute nitric acid (Merck, 65\%) and $0.5 \mathrm{ml}$ of $30 \% \mathrm{H}_{2} \mathrm{O}_{2}$ were added. The mixture of oil and acid was shaken at $50 \mathrm{~Hz}$ for $60 \mathrm{~s}$ with mixer in polypropylene containers until two layers were mixed thoroughly. All polypropylene containers were put in a shaking water bath at $60^{\circ} \mathrm{C}$ for 1.5 hours. After centrifugation in special test tubes at 4,400 rpm for $8 \mathrm{~min}$, the solution layer including lower acid was retreated with a pipette and filled by adding deionized water for up to a final volume of $25 \mathrm{ml}$. Then it was directly charged into the auto sampler of the ICP-AES device. After that, the determinations were performed at $228.802 \mathrm{~nm}$ wavelengths for $\mathrm{Cd}$, at $220.353 \mathrm{~nm}$ for $\mathrm{Pb}$, and at $231.604 \mathrm{~nm}$ for $\mathrm{Ni}$.

Working conditions of ICP-AES device:

- Varian-Vista radio frequency power: 0.7-1.5 kW (1.2$1.3 \mathrm{~kW}$ for axial);

- plasma gas flow rate (Ar): $10.5-15 \mathrm{l} \cdot \mathrm{min}^{-1}$ (radial) and $15 \mathrm{l} \cdot \mathrm{min}^{-1}$ (axial);

- auxiliary gas flow rate (Ar): $1.5 \mathrm{I} \cdot \mathrm{min}^{-1}$;

- viewing height: 5-12 mm;

- copy and reading time: $3 \mathrm{~s}$ (max. $100 \mathrm{~s}$ ) and 1-5 s (max. 60 s), respectively.

For determination of inorganic As, emission signals of the $\mathrm{As}$ (III) can be registered at four wavelengths of $189.0 \mathrm{~nm}, 193.7 \mathrm{~nm}, 197.2 \mathrm{~nm}$, and $288.8 \mathrm{~nm}$. The highest intensity was revealed at $193.7 \mathrm{~nm}$. The result was in good conformity with previous studies (Gettar et al., 2000). 
Determination of inorganic and organic anionic arsenic compounds in water with ion chromatography method concerns hydride generation-inductively coupled plasma emission spectrometry, thus it was selected for the further experiments.

\section{Total arsenic determination}

Samples for investigation were prepared during total digestion in the following way. The first $0.5 \mathrm{~g}$ of dry weight sample was put into $50 \mathrm{ml}$ centrifuge tubes of polypropylene. Next, $2.5 \mathrm{ml}$ of Aristar nitric acid and $4 \mathrm{ml}$ of Suprapur hydrogen peroxide were added to the sample. Then microwave digestion was done by means of CEM Mars5 Microwave System.

When digestion was conducted, dilution of sample was made with double distilled deionized water with rhodium $\left.\left(0.02 \mathrm{ml} \text { of solution with rhodium content of } 10 \mathrm{mg}^{-1}\right)^{-1}\right)$ according to the internal standard. The volume of final diluted sample is $25 \mathrm{ml}$ (Jafari Moghadam and Ziarati, 2016).

\section{Analysis}

An Agilent 7500c ICP-MS device was used to measure the content of As. Hydrogen was taken as collision and reaction gas. CEM Mars5 Microwave System was used to extract samples. For this purpose 1\% Aristar nitric acid and 1\% Suprapur hydrogen peroxide were taken (Ziarati and Tosifi, 2014). Extractable As was determined using the supernatant to improve chromatographic resolution. Such improvement was obtained because the supernatant oxidizes arsenite to arsenate which elutes at certain distance from monomethylarsonous acid (MMA) and dimethylarsinous acid (DMA), while arsenite elutes adjacent to MMA and DMA. Hamilton PRP X 100 anion exchange column using phosphate buffer was applied for analysis of As samples. T-piece was used to add solution of indium $\left(0.01 \mathrm{mg} \cdot \mathrm{kg}^{-1}\right.$ content) in $1 \%$ nitric acid. The mentioned solution was taken as an internal standard (Jafari Moghadam and Ziarati, 2016).

Standard solution aliquots of $0.1 \mathrm{ml}$ containing known amounts (10-100) $\mu \mathrm{g} \cdot \mathrm{kg}^{-1}$ of DMA were subjected to liquid chromatography coupled with ICP-MS method under the same conditions as the supernatants. Identification by retention time was performed by means of single sample standards of DMA, MMA and $\mathrm{As}(\mathrm{V})$. Calibration standard solutions including six As samples at different concentrations ( 1 ppb, 5 ppb, 10 ppb, 50 ppb, 100 ppb and $200 \mathrm{ppb}$ ) were made and analysed. The chromatogram for the $10 \mathrm{ppb}$ calibration standard ( $5 \mu$ injection) has shown that these six As samples were well enough separated in $4 \mathrm{~min}$. The supernatant aliquots of $0.1 \mathrm{ml}$ were applied into the column as they were. As quantification was carried out using peak areas.

\section{Total As determination}

Every $10^{\text {th }}$ sample was selected for digestion. It was digested in duplicate and used for measurements. Each batch was collected from procedural blanks, spiked samples and certified reference materials (Jafari Moghadam and Ziarati, 2016).

Spiked samples were used for recovery estimate purposes. Spike recovery values ranged between $80 \%$ and $120 \%$ were taken as the mark to accept data. For a given sample the replicate values' relative standard deviation had to be less than $20 \%$. Thus, each analytical batch had to provide reference material results within the certified range.

The limit of detection was established on the deviation equal to value of standard deviation of the signal from procedural blanks multiplied on three. Then its correction was made according to sample weight and dilution.

\section{Statistical method}

One-parametric Kruskal-Wallis/Mann-Whitney U tests were carried out in order to make comparison of differences between objects. Non-parametric multiple comparison test (Dunn's test) was utilized for specification of result statistical significance at $\alpha=0.05$. The GLM procedure was carried out in order to analyse different metal treatments with means separated by Duncan's multiple range test at $p<0.05$. Correlation analysis was performed using the CORR procedure with means separated at $p<0.05$.

\section{Results and discussion}

Results were determined as dry weight of three replicates in each test in form of (mean value (MV) \pm standard error (SE)). Samples were analysed with wet digestion method. Material preparation itself and analysis of heavy metals contents were all performed in accordance with standardized international protocols. Samples were analysed using ICPAES method. Contents of $\mathrm{Pb}, \mathrm{Cd}, \mathrm{Ni}$ and $\mathrm{As}$ in samples of Italian olive oil are given in Table 1.

Obtained results revealed that the highest $\mathrm{Pb}$ concentration was registered in samples of Italian fungiflavoured olive oil - $12.3301 \pm 0.112 \mu \mathrm{g} \cdot \mathrm{g}^{-1}$. The lowest $\mathrm{Pb}$ concentration was registered in pepper flavoured sample being equal to $0.984 \mu \mathrm{g} \cdot \mathrm{g}^{-1}$. The highest content of $\mathrm{Cd}$ was also registered in fungi-flavoured olive oil samples - $1.004 \pm 0.0123 \mu \mathrm{g} \cdot \mathrm{g}^{-1}$. The highest detected

Table 1 Content of heavy metals in various samples of Italian olive oil, (MV $\pm \mathrm{SE}) \mu \mathrm{g} \cdot \mathrm{g}^{-1}$

\begin{tabular}{|c|c|c|c|c|}
\hline \multirow[t]{2}{*}{ Heavy metals } & \multicolumn{3}{|c|}{ Olive oil samples flavoured with } & \multirow[t]{2}{*}{ Non-flavoured olive oi } \\
\hline & pepper & fungi & vegetable & \\
\hline $\mathbf{P b}$ & $(0.984 \pm 0.091)$ & $(12.3301 \pm 0.112)^{a}$ & $(10.762 \pm 0.088)^{b}$ & $(10.111 \pm 0.034) b$ \\
\hline Cd & Not detectable & $(1.004 \pm 0.0123)^{a}$ & $(0.0876 \pm 0.004)^{b}$ & $(0.0967 \pm 0.0054) b$ \\
\hline $\mathbf{N i}$ & Not detectable & $(10.231 \pm 0.0143)^{b}$ & $(12.349 \pm 0.128)^{b}$ & $(14.180 \pm 0.011) a$ \\
\hline As & $(0.00020 \pm 0.00001)$ & $(0.00040 \pm 0.00001)^{a}$ & $(0.00030 \pm 0.00001)^{a}$ & $(0.00040 \pm 0.00001) a$ \\
\hline
\end{tabular}


content of $\mathrm{Ni}$ was registered in non-flavoured olive oil $14.180 \pm 0.011 \mu \mathrm{g} \cdot \mathrm{g}^{-1}$ and the highest content of As was registered both in non-flavoured and fungi-flavoured oil samples. Four popular Iranian brands were selected and analysed. Data in Table 2 show that the highest content of $\mathrm{Pb}$ in Iranian olive oil was registered in the fourth brand $18.783 \pm 0.016 \mu \mathrm{g} \cdot \mathrm{g}^{-1}$; the lowest content was registered in the third brand $-11.209 \pm 0.054 \mu \mathrm{g} \cdot \mathrm{g}^{-1}$. It can be clearly seen that the highest content of $\mathrm{Cd}$ was observed in the second brand $-4.181 \pm 0.042 \mu \mathrm{g} \cdot \mathrm{g}^{-1}$. Table 2 indicates that the fourth brand shows the highest Ni content $-14.444 \pm 0.2831 \mu \mathrm{g} \cdot \mathrm{g}^{-1}$. The highest amount of As was observed in the fourth brand $-0.0050 \pm-0.0002 \mu \mathrm{g} \cdot \mathrm{g}^{-1}$.

Results of comparison of heavy metals content in Iranian and Italian samples are represented in Table 3. They show that $\mathrm{Pb}, \mathrm{Cd}$ and As contents in investigated samples of Italian olive oil are significantly different in comparison to Iranian ones. All determined heavy metals were registered in Iranian olive oil samples with higher contents than in Italian ones, indicating that the risk assessment of olive oils consumed in Iran should be considered seriously. The content of $\mathrm{Pb}$ in all flavoured and non-flavoured Iranian oil samples was $14.944 \pm 0.045 \mu \mathrm{g} \cdot \mathrm{g}^{-1}$. This was merely $8.546 \pm 0.043 \mu \mathrm{g} \cdot \mathrm{g}^{-1}$ in Italian oil samples, which is much lower. The content of $\mathrm{Cd}$ in Iranian oil samples was $3.362 \pm 0.032 \mu \mathrm{g} \cdot \mathrm{g}^{-1}$, which is ten times higher than in investigated Italian oil samples $(p<0.005)$.

According to results of variance analysis of obtained data, $\mathrm{Pb}, \mathrm{Cd}, \mathrm{Ni}$ and $\mathrm{As}$ concentrations in olive oil samples were strongly influenced by specific origin of the producer. Flavour type also significantly affected the heavy metals content in Italian olive oil samples. There was a positive correlation registered between the olive oil manufacturing and quality level of packaging equipment - Iranian oil samples by new producers with modern equipment have shown lower heavy metals contents in majority of cases $(p<0.05)$. Furthermore, there was observed a positive correlation between the storage time and heavy metals content. This interrelation was especially sharp for Iranian olive oil samples (Table 4) heavy metals contents (especially $\mathrm{Pb}$ and $\mathrm{Cd}$ ) in oils stored for twelve months were much higher in comparison with the freshly collected samples.

In general, it can be seen that the contents of $\mathrm{Pb}, \mathrm{Cd}$, $\mathrm{Ni}$ and $\mathrm{As}$ in Italian samples did not exceed the limits set by Codex Alimentarius and USDA. The mean amount of $\mathrm{Pb}$ in both groups exceeded the amount set by Codex Alimentarius and USDA, except for the samples flavoured by pepper (Jafari Moghadam and Ziarati, 2016). The mean content of $\mathrm{Ni}$ in Iranian brands was higher than in Italian brands, yet no significant differences were observed. Considering the mean content of $\mathrm{Cd}$ and As, they showed significant differences $(p<0.05)$. The mean levels of $\mathrm{Pb}$, $\mathrm{Cd}$ and $\mathrm{Ni}$ in Italian samples were lower than standards. Simultaneously, the As content in Iranian olive oil samples was a little higher than in Italian ones, however, both were lower than the maximum permissible level and showed no significant difference. The mean amount of $\mathrm{Pb}$ in both groups of samples exceeded those values set by Codex Alimentarius and USDA except for the pepper-flavoured samples (Jafari Moghadam and Ziarati, 2016). The mean content of $\mathrm{Ni}$ in Iranian olive oil samples was higher than in Italian ones, but results showed no significant differences in values. At the same time, results showed significant differences $(p<0.05)$ in the mean content of $\mathrm{Cd}$ and As.

Investigation results showed that there was no detectable concentration of $\mathrm{Cd}$ in pepper-flavoured olive oil samples. Furthermore, the mean level of $\mathrm{Cd}$ content arises

Table 2 Content of heavy metals in various samples of Iranian olive oils, (MV $\pm \mathrm{SE}) \mu \mathrm{g} \cdot \mathrm{g}^{-1}$

\begin{tabular}{|l||c|c|c|c|}
\hline \multirow{2}{*}{ Heavy metals } & \multicolumn{4}{c|}{ Olive oil samples } \\
\cline { 2 - 5 } & series 1 & series 2 & series 3 & series 4 \\
\hline \hline Pb & $(15.893 \pm 0.098)^{\mathrm{a}}$ & $(13.892 \pm 0.067)^{\mathrm{b}}$ & $(11.209 \pm 0.054)^{\mathrm{b}}$ & $(18.783 \pm 0.016)^{\mathrm{a}}$ \\
\hline $\mathbf{C d}$ & $(3.234 \pm 0.044)^{\mathrm{b}}$ & $(4.181 \pm 0.042)^{\mathrm{a}}$ & $(2.001 \pm 0.0022)^{\mathrm{c}}$ & $(4.032 \pm 0.014)^{\mathrm{a}}$ \\
\hline $\mathbf{N i}$ & $(12.354 \pm 0.036)^{\mathrm{b}}$ & $(10.542 \pm 0.072)^{\mathrm{c}}$ & $(9.786 \pm 0.0102)^{\mathrm{c}}$ & $(14.444 \pm 0.283)^{\mathrm{a}}$ \\
\hline As & $(0.0040 \pm 0.0001)^{\mathrm{b}}$ & $(0.0030 \pm 0.0001)^{\mathrm{c}}$ & $(0.0030 \pm 0.0001)^{\mathrm{c}}$ & $(0.0050 \pm 0.0002)^{\mathrm{a}}$ \\
\hline
\end{tabular}

Table 3 Content of heavy metals in Iranian and Italian olive oils, (MV $\pm \mathrm{SE}) \mu \mathrm{g} \cdot \mathrm{g}^{-1}$

\begin{tabular}{|l||c|c|c|c|}
\hline \multirow{2}{*}{ Olive oil samples } & \multicolumn{4}{|c|}{ Heavy metals } \\
\cline { 2 - 5 } & $\mathbf{P b}$ & $\mathbf{C d}$ & $\mathbf{N i}$ & As \\
\hline \hline Italian & $(8.546 \pm 0.043)^{\mathrm{b}}$ & $(0.396 \pm 0.031)^{\mathrm{b}}$ & $(12.253 \pm 0.078)^{\mathrm{b}}$ & $(0.00020 \pm 0.00001)^{\mathrm{b}}$ \\
\hline Iranian & $(14.944 \pm 0.045)^{\mathrm{a}}$ & $(3.362 \pm 0.032)^{\mathrm{a}}$ & $(9.579 \pm 0.065)^{\mathrm{a}}$ & $(0.0039 \pm 0.0002)^{\mathrm{a}}$ \\
\hline
\end{tabular}

Table 4 Content of cadmium and lead during storage time in olive oil samples

\begin{tabular}{|l||c|c|c|c|}
\hline \multirow{2}{*}{ Heavy metals } & \multicolumn{4}{|c|}{ Storage time (months) } \\
\cline { 2 - 5 } & $\mathbf{1}$ & $\mathbf{3}$ & $\mathbf{6}$ & $\mathbf{1 2}$ \\
\hline $\mathbf{P b}$ & $(14.221 \pm 0.028)^{\mathrm{b}}$ & $(15.128 \pm 0.033)^{\mathrm{b}}$ & $(15.867 \pm 0.081)^{\mathrm{b}}$ & $(27.111 \pm 0.102)^{\mathrm{a}}$ \\
\hline $\mathbf{C d}$ & $(2.989 \pm 0.032)^{\mathrm{c}}$ & $(3.156 \pm 0.022)^{\mathrm{c}}$ & $(4.001 \pm 0.005)^{\mathrm{b}}$ & $(4.989 \pm 0.011)^{\mathrm{a}}$ \\
\hline
\end{tabular}


to $1.004 \pm 0.0123 \mu \mathrm{g} \cdot \mathrm{g}^{-1}$ in the fungi-flavoured olive oils, exceeding the maximum permissible level set by FAO and WHO. The mean contents of $\mathrm{Cd}$ in vegetable-flavoured and non-flavoured olive oils are equal to $0.0876 \pm 0.004 \mu \mathrm{g} \cdot \mathrm{g}^{-1}$ and $0.0967 \pm 0.0054 \mu \mathrm{g} \cdot \mathrm{g}^{-1}$, respectively. Results showed no significant differences between them $(p<0.05)$.

The $\mathrm{Cd}$ content was sharply registered in fungi-flavoured olive oil samples, which is probably related to contamination of fungi itself. It could also mean that peppers are stronger than fungi at removing the heavy metals and fungi may saturate metals more in terms of olive oils. Investigation results revealed that all heavy metals contents in pepperflavoured olive oil samples were significantly lower than in other samples $(p<0.03)$. The highest mean content of $\mathrm{Ni}$ was observed in non-flavoured samples. Results show no detectable content of $\mathrm{Ni}$ in pepper-flavoured olive oils. This significant difference is a very remarkable finding. The mean content of $\mathrm{Pb}$ in fungi-flavoured olive oil samples was $12.33 \pm 0.66 \mu \mathrm{g} \cdot \mathrm{g}^{-1}$; it was only $0.984 \pm 0.091 \mu \mathrm{g} \cdot \mathrm{g}^{-1}$ in pepperflavoured samples, which is 12.5 times less with significant difference $(p<0.01)$. The ability of fungi to accumulate high concentrations of traces and some heavy metals is relatively unknown.

\section{Conclusion}

The results of investigation revealed that adding pepper to olive oil as a flavour significantly reduces heavy metals content. The further investigation of the heavy metals removal mechanism is strongly suggested. Nutrition and protection of vegetables and crops have to be performed properly. Heavy metals have toxic potential. However, their detrimental impact is shown in organism only after several years of being exposed to them. Observation of heavy metals in oil is vital, since it can help to develop preventive measures for avoiding excessive accumulation of them in human food chain. Companies treating products before selling them to markets should become aware of this and take the adequate steps for the manufacturing process improvement.

\section{Acknowledgment}

Authors acknowledge gratefully The Islamic Azad University, Tehran Medical Branch, Tehran, Iran.

\section{References}

BECERRA-HERRERA, M. - SÁNCHEZ-ASTUDILLO, M. - BELTRÁN, R. SAYAGO, A. 2014. Determination of phenolic compounds in olive oil: New method based on liquid-liquid micro extraction and ultrahigh performance liquid chromatography-triple-quadrupole mass spectrometry. In Journal of Food Science and Technology, vol. 57, no. 1, pp. 49-57.

CANABATE-DIAZ, B. - SEGURA CARRETERO, A. - FERNANDEZGUTIERREZ, A. - BELMONTE VEGA, A. - GARRIDO FRENICH, A. MARTINEZ VIDAL, J. L. - DURAN MARTOS, J. 2007. Separation and determination of sterols in olive oil by HPLC-MS. In Food Chemistry, vol. 102, no. 3, pp. 593-598.

CHOOTO, P. - MUAKTHONG, D. - INNUPHAT, C. WARARATTANANURAK, P. 2016. Determination of inorganic arsenic species by hydride generation-inductively coupled plasma optical emission spectrometry. In ScienceAsia, vol. 42, pp. 275-282.
CODEX ALIMENTARIUS COMMISSION. 2001. Report of the $33^{\text {rd }}$ session of the codex committee on food additives and contaminants. Rome, Italy : Food and Agriculture Organization of the United Nations/World Health Organization, $289 \mathrm{pp}$.

CODEX STAN 33-1981. Standard for olive oils and olive pomace oils. COUNCIL OF EUROPE. 2001. Guidelines on metals and alloys used as food contact material. France, Strasbourg : Council of Europe, 88 pp. COVAS, M. I. 2007. Olive oil and the cardiovascular system. In Pharmacological Research, vol. 55, pp. 175-186.

EUROPEAN COMMISSION, Directorate-General for Agriculture and Rural Development Latest update: July 2012.

FARZIN, L. - MOASSESI, M. E. 2014. Determination of metal contents in edible vegetable oils produced in Iran using microwave-assisted acid digestion. In Journal of Applied Chemical Research, vol. 8, no. 3, pp. 35-43.

FLORES, J. C. M. - ORTIZ, M. D. - RUIZ, J. A. - PEINADO, F. M. FERNANDEZ, I. G. 2009. Study of heavy metal and arsenic concentrations in olive farm soils, Sierra Mágina, Jaen, Spain. In Acta Agronomica, vol. 58, no. 4, pp. 303-307. (In Spanish: Estudio de metales pesados y arsénico en los suelos de olivar de Sierra Mágina, Jaén (España)).

GARCIA MESA, J. A. - MATEOS, R. 2007. Direct automatic determination of bitterness and total phenolic compounds in virgin olive oil using a pH-based flow-injection analysis system. In Journal of Agricultural and Food Chemistry, vol. 55, no. 10, pp. 3863-3868.

GETTAR, R. T. - GARAVAGLIA, R. N. - GAUTIER, E. A. - BATISTONI, D. A. 2000. Determination of inorganic and organic anionic arsenic species in water by ion chromatography coupled to hydride generation-inductively coupled plasma emission spectrometry. In Journal of Chromatography A, vol. 884, no. 1-2, pp. 211-221.

GODOY-CABALLERO, M. - GALEANO-DÍAZ, T. - ISABEL ACEDOVALENZUELA, M. 2012. Simple and fast determination of phenolic compounds from different varieties of olive oil by nonaqueous capillary electrophoresis with UV-visible and fluorescence detection. In Journal of Separation Science, vol. 35, no. 24, pp. 3529-3539.

HUANG, C. L. - SUMPIO, B. E. 2008. Olive oil, the Mediterranean diet, and cardiovascular health. In Journal of the American College of Surgeons, vol. 207, no. 3, pp. 407-416.

INTERNATIONAL OLIVE COUNCIL. 2012. Health benefits of olives and olive oil. A review of the research commissioned by the International Olive Council, $11 \mathrm{pp}$.

JAFARI MOGHADAM, R. - ZIARATI, P. 2016. Reduction of arsenic content in imported polished rice: Association of cooking method. In Journal of Chemical and Pharmaceutical Research, vol. 8, no. 4, pp. 622-627.

MAILER, R. 2006. Chemistry and quality of olive oil. In Primefacts, vol. 227, pp. 1-4.

MIRMOHAMMAD MAKKI, F. - ZIARATI, P. 2014. Determination of histamine and heavy metal concentrations in tomato pastes and fresh tomato (Solanum lycopersicum) in Iran. In Biosciences Biotechnology Research Asia, vol. 11, no. 2, pp. 537-544.

PEHLIVAN, E. - ARSLAN, G. - GODE, F. - ALTUN, T. - ÖZCAN, M. 2008. Determination of some inorganic metals in edible vegetable oils by inductively coupled plasma atomic emission spectroscopy (ICPAES). In Grasas y Aceites, vol. 59, no. 3, pp. 239-244.

RODRÍGUEZ-MORATÓ, J. - XICOTA, L. - FITÓ, M. - FARRÉ, M. DIERSSEN, M. - DE LA TORRE, R. 2015. Potential role of olive oil phenolic compounds in the prevention of neurodegenerative diseases. In Molecules, vol. 20, pp. 4655-4680.

SHAHGHOLI, H. - MAKARIAN, H. - SHOKATI, B. - TALAEI, G. H. ASGHARIPOUR, M. R. 2015. Do tillage methods affect germination and species similarity of soil weed seeds bank? In Acta Technologica Agriculturae, vol. 4, pp. 97-101. 
SINGH, N. - KUMAR, D. - SAHU, A. P. 2007. Arsenic in the environment: Effects on human health and possible prevention. In Journal of Environmental Biology, vol. 28, no. 2, pp. 359-365.

UNITED STATES DEPARTMENT OF AGRICULTURE. 2010. United States standards for grades of olive oil and olive-pomace oil. United States, Washington: USDA, $19 \mathrm{pp}$.

VAMBOL, S. - VAMBOL, V. - BOGDANOV, I. - SUCHIKOVA, Y. RASHKEVICH, N. 2017. Research of the influence of decomposition of wastes of polymers with nano inclusions on the atmosphere. In Eastern-European Journal of Enterprise Technologies, vol. 6, no. 10(90), pp. 57-64.

VAMBOL, S. - VAMBOL, V. - KONDRATENKO, O. - KOLOSKOV, V. SUCHIKOVA, Y. 2018. Substantiation of expedience of application of high-temperature utilization of used tires for liquefied methane production. In Archives of Materials Science and Engineering, vol. 87, no. 2, pp. 77-84.

WATERMAN, E. - LOCKWOOD, B. 2007. Active components and clinical applications of olive oil. In Alternative Medicine Review, vol. 12, no. 4, pp. 331-342.

WORLD HEALTH ORGANIZATION. 2011. Arsenic in drinking-water: Background document for development of WHO guidelines for drinking-water quality. Switzerland, Geneva : World Health Organization, $24 \mathrm{pp}$.
ZHANG, P. - XIE, H. L. - ZHU, Q. H. - NIE, X. D. 2014. Determination of heavy metal elements in edible olive oil by ICP-MS. In Modern Food Science and Technology, vol. 30, no. 3, pp. 206-209.

ZIARATI, P. - GHASEMYNEZHAD-SHANDERMAN, S. S. 2014. Mineral contents in Pleurotus (Oyster Mushroom): Association of cooking method. In International Journal of Plant, Animal and Environmental Sciences, vol. 4, no. 2, pp. 496-501.

ZIARATI, P. - TOSIFI, S. 2014. Comparing some physical and chemical properties of green olive (Olea europea L.) in Iran association with ecological conditions. In International Journal of Plant, Animal and Environmental Sciences, vol. 4, no. 2, pp. 519-528.

ZIARATI, P. 2012. Determination of contaminants in some Iranian popular herbal medicines. In Journal of Environmental and Analytical Toxicology, vol. 2, no. 1, pp. 1-3. 